\title{
PERBEDAAN KOMBINASI MASSAGE TENGKUK DAN OKSITOSIN DENGAN MASSAGE OKSITOSIN TERHADAP WAKTU PENGELUARAN ASI PADA IBU POST PARTUM
}

\section{DIFFERENCES COMBINATION NECK MASSAGE AND OXYTOCIN WITH OXYTOCIN MASSAGE TO THE WITHDRAWAL TIME OF BREAST MILK POST PARTUM}

\author{
Yeyen Wulandari Dhanio', Rafika², Siti Hadijah Batjo' \\ ${ }^{1}$ Poltekkes Kemenkes Palu \\ ${ }^{2}$ Poltekkes Kemenkes Makassar \\ *) E-mail korespondensi: rafikauddinramli@gmail.com
}

\begin{abstract}
Expenditure of MILK is influenced by the stress factor to the disruption of the peace and mind of the mother, inhibiting the secretion of oxytocin and prolactin. Thus, early feeding is constrained due to production and less BREAST ejection on the first day of childbirth. Research conducted in BPM Amanah for 6 weeks. The research aims to determine the difference in combination massage and massage oxytocin with an oxytocin massage to the postpartum mother in BPM Amanah. Pre-Experimental Research type with One-Shot Case Study design. The sample number of 48 people, taken with the consecutive sampling technique and divided into 24 respondents per group. The intervention was carried out after 2 hours of postpartum and observed the time of the first expenditure of MILK after the intervention, then the data was analyzed univariate and bivariate using the Mann Whitney test. The results of the study acquired the time of the combination of breast milk and massage oxytocin that is $<6$ hours and 18 respondents, $6-24$ hours as many as 5 respondents and $>24$ hours as many as 1 respondent and the time of production of breast milk massage oxytocin that is $<6$ hours as much as 13 respondents, $6-24$ hours as much as 9 respondents and $>24$ Statistical test results are obtained at the time of breast milk withdrawal given the combination of massage and massage Okcitosin 3.35 jam and massage oxytocin 6.87 hours. Mann Whitney test Results obtained $\rho$-value 0.026 . In conclusion, there is a time difference in the expenditure of breast milk given the combination of massage and massage oxytocin with massage oxytocin after IV childbirth. Based on the results of research suggested for midwives in BPM Amanah for the need to be socialized to the mother postpartum and the application of a combination massage and massage oxytocin.
\end{abstract}

Keywords: massage oxytocin, neck massage, postpartum, withdrawal time

\section{ABSTRAK}

Pengeluaran ASI dipengaruhi faktor stress sehingga terganggunya ketenangan jiwa dan pikiran ibu, menghambat sekresi oksitosin dan prolaktin. Sehingga pemberian ASI secara dini terkendala akibat produksi dan ejeksi ASI lebih sedikit pada hari pertama melahirkan. Penelitian dilakukan di BPM Amanah selama 6 minggu. Tujuan penelitian untuk mengetahui perbedaan kombinasi massage tengkuk dan massage oksitosin dengan massage oksitosin terhadap waktu pengeluaran ASI pada ibu postpartum di BPM Amanah. Jenis penelitian Pre-Exsperimental dengan desain One-Shot Case Study. Jumlah sampel 48 orang, diambil dengan teknik consecutive sampling dan dibagi menjadi 24 responden setiap kelompoknya. Pemberian intervensi dilakukan setelah 2 jam postpartum dan diobservasi waktu pengeluaran ASI pertama setelah pemberian intervensi, kemudian data dianalisis secara univariat dan bivariat menggunakan uji Mann Whitney. Hasil penelitian diperoleh waktu pengeluaran ASI kelompok kombinasi massage tengkuk dan massage oksitosin yang <6 jam sebanyak 18 responden, 6-24 jam sebanyak 5 responden dan >24 jam sebanyak 1 responden serta waktu pengeluaran ASI kelompok massage oksitosin yang <6 jam sebanyak 13 responden, $6-24$ jam sebanyak 9 responden dan $>24$ jam sebanyak 2 responden. Hasil uji statistik diperoleh rerata waktu pengeluaran ASI ibu yang diberikan kombinasi massage tengkuk dan massage oksitosin 3,35 jam serta massage oksitosin 6,87 jam. Hasil uji Mann Whitney diperoleh $\rho$-value 0,026 . Kesimpulan, ada perbedaan waktu pengeluaran ASI yang diberikan kombinasi massage tengkuk dan massage oksitosin dengan massage oksitosin setelah kala IV persalinan. Berdasarkan hasil penelitian disarankan bagi petugas bidan di BPM Amanah untuk perlunya diadakan sosialisasi kepada ibu postpartum dan penerapan kombinasi massage tengkuk dan massage oksitosin.

Kata Kunci : massage oksitosin, massage tengkuk, postpartum, waktu pengeluaran ASI

\section{PENDAHULUAN}

Menyusui

merupakan proses

pemberian nutrisi berupa air susu ibu (ASI) yang bersumber dari payudara ibu untuk mencukupi seluruh unsur kebutuhan bayi berupa nutrisi, hormon, unsur kekebalan, faktor pertumbuhan, anti alergi dan anti inflamasi (Syandi, 2017). ASI yang disekresikan oleh kedua belah kelenjar payudara ibu berupa makanan alamiah atau susu terbaik bernutrisi dan berenergi tinggi yang mudah dicerna dan mengandung komposisi nutrisi yang seimbang dan sempurna untuk tumbuh kembang bayi yang tersedia setiap saat, siap disajikan dalam suhu yang tepat dan bebas dari kontaminasi (Wiji, 2013).

Pentingnya memberikan ASI kepada bayi tercermin pada rekomendasi World Health Organization (WHO) yang 
menyatakan bahwa untuk menyediakan makanan yang ideal bagi pertumbuhan dan perkembangan yang sehat bagi bayi, menyusui menjadi cara yang tidak tertandingi. ASI sebagai sumber nutrisi terbaik untuk bayi dan ASI mengandung antibodi yang melindungi bayi dari berbagai macam penyakit. Demikian dihimbau agar setiap ibu memberikan ASI eksklusif sampai bayinya berusia 6 bulan (World Health Organization, 2016).

Upaya memaksimalkan pencapaian dalam agenda Suistainable Development Goals (SDGs) pada tahun 2030 tentang target angka kematian anak usia kurang dari 5 tahun adalah < 25 per 1000 kelahiran hidup, ASI eksklusif penting untuk dipraktikkan secara universal, sehingga dapat menyelamatkan $13 \%$ anak dari seluruh jumlah kematian anak usia kurang dari 5 tahun (Tadesse, Mesfin and Chane, 2016).

Hasil laporan Riset Kesehatan Dasar (RISKESDAS) menunjukkan bahwa cakupan ASI eksklusif pada bayi umur 6 bulan di Indonesia mengalami peningkatan dari $15,3 \%$ tahun 2010 menjadi $30,2 \%$ pada tahun 2013, demikian pula inisiasi menyusu dini $<1$ jam meningkat dari 29,3\% tahun 2010 menjadi 34,5\% tahun 2013, meskipun demikian angka tersebut masih ada dibawah target yang diharapkan yaitu $80 \%$ (Badan Penelitian dan Pengembangan Departemen Kesehatan RI, 2013). Tahun 2015 di provinsi Sulawesi Tengah tercatat dari jumlah 36.554 bayi, cakupan pemberian ASI eksklusif sebesar 20.455 bayi atau 56,0\% dan pada 2016 meningkat dari jumlah bayi 34.342 bayi, cakupan pemberian ASI eksklusifnya sebesar 19.345 bayi atau $56,3 \%$ (Dinas Kesehatan Kota Palu, 2016). Cakupan ASI eksklusif di Kota Palu adalah $64,4 \%$ dengan wilayah yang memiliki cakupan paling tinggi adalah wilayah kerja Puskesmas Tawaeli, yaitu $85,49 \%$ dan yang terendah adalah wilayah kerja Puskesmas Bulili, yaitu 49,53\% (Dinas Kesehatan Kota Palu, 2016).

Pengeluaran ASI menjadi suatu interaksi yang sangat kompleks antara rangsangan mekanik, saraf dan bermacammacam hormon yang telah dimulai saat fetus sampai dengan masa pasca persalinan. Konsentrasi hormon yang menstimulus perkembangan payudara selama wanita hamil (estrogen, progesteron, human chorionic gonadotropin, kotrisol dan insulin) dapat menurun dengan cepat setelah bayi lahir. Akibatnya, diperlukan rangsangan berupa hisapan bayi untuk menstimulus produksi hormon untuk menghasilkan ASI (Asih and Risneni, 2016). Terdapat sembilan faktor yang dapat mempengaruhi kelancaran produksi dan pengeluaran ASI yaitu makanan, ketenangan jiwa dan pikiran, penggunaan alat kontrasepsi, perawatan payudara, anatomi payudara, faktor fisiologi, faktor isapan atau frekuensi menyusui dan konsumsi rokok dan alkohol (Zerlina, 2014).

Kendala dalam pemberian ASI secara dini dikarenakan produksi dan ejeksi ASI lebih sedikit pada hari pertama setelah melahirkan. Selain itu, terdapat enam alasan lain ibu tidak menyusui bayinya pada hari pertama menyusui disebabkan oleh kecemasan, kurangnya rasa percaya diri dan ketakutan ibu akan kurangnya produksi ASI serta kurangnya pengetahuan ibu, dukungan keluarga dan lingkungan tentang proses menyusui (Badriah, 2014). Permasalahan ASI yang tidak keluar pada hari kesatu hingga ketiga ini seharusnya dapat di antisipasi sejak kehamilan melalui konseling laktasi. Sekitar $60 \%$ masyarakat tahu informasi tentang ASI dan baru ada sekitar $40 \%$ tenaga kesehatan terlatih yang bisa memberikan konseling menyusui. Sehingga perlu adanya solusi untuk ibu yang terlanjur khawatir dan mencegah pemberian susu formula karena masalah pemberian ASI dini yang disebabkan ASI tidak keluar di hari pertama (Ulfah, 2013).

Studi kualitatif yang dilakukan pada 12 ibu postpartum pada dua puskesmas di Kota Semarang, menunjukkan bahwa 9 orang ibu gagal melakukan pemberian ASI eksklusif karena telah memberikan Pengganti ASI (P-ASI) dan Makanan Pendamping ASI (MP-ASI) pada bayinya. Permasalahan yang muncul dalam studi tersebut adalah ASI kurang, ASI tidak keluar pada hari pertama dan ibu tidak sabar untuk memberikan ASI saja (Noer, Muis and Aruben, 2011).

Hormon oksitosin dan prolaktin yang diperlukan dapat diperoleh melalui stimulus yang diberikan berupa isapan bayi pada ujung-ujung saraf sensoris yang berfungsi sebagai reseptor mekanik. Rangsangan ini dilanjutkan ke hipotalamus untuk merangsang pengeluaran faktor-faktor yang memacu sekresi prolaktin yang merangsang hipofisis anterior untuk mensekresikan prolaktin. Bersama dengan 
pembentukan prolaktin, rangsangan juga dilanjutkan ke hipofisis posterior untuk mensekresikan oksitosin. Rangsangan di puting susu menjadi alasan utama oksitosin dilepaskan (Rini and Kumala, 2016).

Metode atau teknik lain yang dapat digunakan untuk merangsang refleks oksitosin selain hisapan bayi, diantaranya adalah kompres panas untuk mengurangi rasa sakit, massage tengkuk dan punggung agar ibu rileks, massage yang ringan pada payudara, merangsang kulit puting dan membantu ibu untuk rileks (Wiji, 2013). Saat ibu merasa rileks, puas, bahagia, percaya diri bisa memberikan ASI pada bayinya, memikirkan bayinya dengan penuh kasih dan perasaan positif lainnya akan membuat refleks oksitosin bekerja (Asih and Risneni, 2016).

Pemijatan tengkuk dan punggung memberikan kontribusi yang besar bagi ibu nifas. Rasa nyaman yang ibu rasakan akan membantu dalam pengeluaran ASI, sehingga ibu tidak akan merasakan nyeri baik dari hisapan bayi pada payudara maupun kontraksi uterus karena pada pemijatan tengkuk dan punggung mampu mengeluarkan endorfin merupakan senyawa yang menenangkan. Dalam keadaan tenang seperti inilah ibu nifas yang sedang menyusui mampu mempertahankan produksi ASI yang mencukupi bagi bayinya (Wiji, 2013).

Hormon prolaktin dan oksitosin dapat distimulasi melalui massage oksitosin (Albertina and S, 2015). Menurut Suryani dalam penelitiannya di RSUD KRT Setjonegoro Wonosobo menunjukkan bahwa berdasarkan hasil analisis data, ibu yang diberikan massage tengkuk dan massage otot pectoralis mayor terbukti cenderung mengalami peningkatan pengeluaran ASI. Sehingga terdapat manfaat massage tengkuk dan massage otot pectoralis mayor terhadap pengeluaran ASI (Suryani, 2014).

Penelitian yang dilakukan oleh Sebayang di Klinik Pratama Rosni Alizar Medan menyebutkan bahwa massage tengkuk dan kompres hangat payudara terbukti dapat meningkatkan pengeluaran ASI 1-2 kali lebih besar setelah diberikan perlakuan ini (Sebayang, 2017). Pemijatan tengkuk erat kaitannya dengan keberadaan hipofisis dan hipotalamus. Suharto mengemukakan bahwa letak tengkuk yang dekat dengan kepala dan dada dengan aksi dari otot semispinalis yang menimbulkan kontraksi simultan akan mempercepat suplai darah yang mengangkut oksitosin dan prolactin (Suharto, 2011).

Umbarsari dalam penelitiannya juga menyebutkan bahwa waktu pengeluaran ASI pada ibu postpartum normal yang diberikan massage oksitosin adalah 5,15 jam lebih cepat daripada ibu yang tidak diberikan massage oksitosin adalah 8,30 jam. Ini menunjukkan bahwa, baik massage tengkuk maupun massage oksitosin, memiliki pengaruh terhadap waktu dan kelancaran pengeluaran ASI (Umbarsari, 2017).

Melalui upaya pengeluaran ASI dalam mempengaruhi proses produksi dan pengeluarannya, diperlukan rangsangan keputing susu atau melalui pijatan pada tulang belakang ibu akan mereleksasi ketegangan dan menghilangkan stres, dengan begitu akan merangsang pengeluaran prolaktin dan oksitosin dan membantu pengeluaran ASI lebih cepat (Endah and Masdinarsah, 2011). Ketika kadar hormon prolaktin menurun, akan sulit merangsang kembali hormon prolaktin sehingga produksi ASI kurang lancar dan ASI baru akan keluar pada hari ketiga atau lebih (Lestari, Sari and Muthia, 2013).

Puskesmas Sangurara merupakan puskesmas nomor urut ke-3 dengan angka kelahiran tertinggi di Kota Palu pada tahun 2016 yang mencapai $101,0 \%$ atau 984 persalinan dalam 1 tahun. Berdasarkan data Puskesmas Sangurara 2016, persalinan terbanyak berada di Bidan Praktik Mandiri (BPM) wilayah kerja Puskesmas Sangurara (Dinas Kesehatan Provinsi Sulawesi Tengah, 2016). Berdasarkan keterangan yang diperoleh dari salah satu petugas kesehatan di BPM Amanah bahwa bidan telah memberikan tindakan perawatan payudara dan massage oksitosin kepada ibu postpartum yang mengalami hambatan pengeluaran ASI walaupun tidak dilakukan secara rutin oleh petugas dan belum pernah melakukan tindakan massage tengkuk. Tujuan penelitian ini menganalisis perbedaan kombinasi massage tengkuk dan massage oksitosin dengan massage oksitosin terhadap waktu pengeluaran ASI pada ibu postpartum.

\section{METODE}

Desain, tempat, waktu

Penelitian ini merupakan jenis penelitian Pre Exsperimental dengan 
desain penelitian One-Shot Case Study. Kelompok eksperimen dibagi menjadi 2 kelompok, terdapat satu kelompok diberi intervensi kombinasi massage tengkuk dan massage oksitosin, dan terdapat kelompok lain diberi intervensi massage oksitosin. Setelah selesai perlakuan, kedua kelompok diobservasi hasilnya. Penelitian ini dilaksanakan di Bidan Praktik Mandiri (BPM) Amanah Kota Palu pada bulan MeiJuni 2018.

\section{Populasi, sampel, Cara pengambilan sampel}

Populasi dalam penelitian ini adalah seluruh ibu postpartum yang ada di BPM Amanah. Sampel dilakukan penentuan besar sampel dihitung berdasarkan perhitungan metode statistik dengan rumus estimasi dalam penelitian ini ditentukan menggunakan Rumus Estimasi Proporsi (Lemeslow et al., 1997). Sampel berjumlah 48 sampel yang dibagi menjadi 2 kelompok sampel, yaitu 24 responden untuk kelompok kombinasi massage tengkuk dan massage oksitosin dan 24 responden untuk kelompok massage oksitosin. Pengambilan sampel dilakukan dengan menggunakan teknik consecutive sampling dengan kriteria inklusi sampel adalah lbu bersalin dengan umur kehamilan 37-42 minggu, Ibu dengan persalinan tanpa komplikasi. Pengumpulan data dimulai dengan data dikumpulkan melalui observasi yang dilakukan peneliti dengan bantuan bidan yang bertugas. Intervensi yang dilakukan menggunakan SOP selaku alat ukur dalam pemberian intervensi. Adapun bahan dan alat yang digunakan yaitu baby oil sebagai minyak pijat. Prosedur Pengumpulan data diantaranya responden yang memenuhi kriteria inklusi akan diambil sebagai subjek penelitian dan dimasukkan dalam kelompok intervensi. Peneliti menjelaskan penelitian meliputi tujuan, hak dan kewajiban responden serta manfaat penelitian pada responden, kemudian responden yang bersedia berpartisipasi dalam penelitian diberikan informed consent untuk ditandatangani. Pada kelompok intervensi yang akan diberikan kombinasi massage tengkuk dan massage oksitosin. Massage tengkuk dimulai dengan gerakan pertama, menggunakan 3 jari dengan gerakan menggosok dari samping kanan tengkuk dan bahu, dimulai dari prosessus mastodeus sampai acromeon, tangan kiri memegang kepala ibu di bagian samping kiri, ulangi sebanyak 5 kali. Kedua, pemijatan daerah leher belakang (tengkuk) dengan jari-jari dan ibu jari tangan kanan dimulai dari kanan ke kiri medulla oblongata sampai pada pangkal leher, sedangkan tangan kiri menahan dahi, ulangi sebanyak 5 kali. Dan ketiga, pemijatan daerah bahu kanan dan kiri dengan menggunakan jarijari dan ibu jari ke dua tangan pada bahu kanan dan kiri secara bersamaan dan mulai dari pangkal leher sampai ujung bahu, ulangi sebanyak 5 kali. Setiap gerakan ini dilakukan selama 3-5 menit. Kemudian, 5 menit setelah massage tengkuk berakhir, dilanjutkan dengan massage oksitosin dimulai dengan menggunakan kedua ibu jari, mulailah memijat membentuk gerakan melingkar kecil menuju tulang belikat atau daerah dibagian batas bawah gerak ibu selama 3-5 menit. Pada kelompok intervensi yang diberikan massage oksitosin. Massage oksitosin dimulai dengan menggunakan kedua ibu jari, memijat membentuk gerakan melingkar kecil menuju tulang belikat atau daerah dibagian batas bawah gerak ibu selama 3-5 menit. Setelah responden dilakukan intervensi kemudian observasi waktu pengeluaran ASI dan hasil didokumentasikan dilembar observasi.

\section{Pengolahan dan analisis data}

Pengolahan data diantaranya tahap ini untuk memastikan bahwa data yang diperoleh melalui kuesioner telah lengkap, terisi semua dan dapat dibaca dengan baik seperti identitas responden, karakteristik responden dan waktu pengeluaran ASI dan tidak ada kuisioner yang keluarkan (drop out). Setiap data diberi kode pada setiap kelompok untuk memudahkan pada waktu memasukkan data (entry data). Pengkodean lembar karakteristik disesuaikan dengan hasil wawancara responden. Melakukan Tabulating dengan mengelompokkan data sesuai dengan karakteristik serta menghitung, mengelompokkan dan mengidentifikasi waktu pengeluaran ASI pada setiap kelompok penelitian. Cleaning, melakukan pengecekan kembali guna mencegah terjadinya kesalahan pada proses tabulating ataupun coding. Entry, memasukkan data yang telah dikumpulkan ke komputer untuk selanjutnya dilakukan analisis menggunakan program komputerisasi. Analsis Data dengan 
dengan uji univariat setiap variabel dan bivariat dengan uji Mann Whitney.

\section{HASIL}

\section{Karakteristik Responden}

Gambaran karakteristik distribusi responden berdasarkan umur dan paritas pada kelompok kombinasi massage tengkuk dan massage oksitosin maka dapat dilihat pada tabel 01. Berdasarkan data pada Tabel 01 menunjukkan bahwa pada kelompok kombinasi massage tengkuk dan massage oksitosin, karakteristik umur sebagian besar responden berada pada kelompok umur 20-35 tahun sebanyak 20 responden $(83,3 \%)$ dan karakteristik paritas terbanyak adalah multipara sejumlah 18 responden (75\%). Untuk mengetahui gambaran distribusi responden berdasakan umur dan paritas pada kelompok massage oksitosin maka dapat dilihat pada tabel 02 . Berdasarkan data pada Tabel 02 menunjukkan bahwa pada kelompok massage oksitosin, karakteristik umur sebagian besar responden berada pada kelompok umur 20-35 tahun sebanyak 22 responden $(91,7 \%)$ dan karakteristik paritas terbanyak adalah multipara sebanyak 19 responden $(79,2 \%)$.

Hasil analisis waktu pengeluaran ASI pada setiap kelompok intervensi dapat dilihat tabel 03. Berdasarkan Tabel 03 menunjukkan bahwa pada kelompok intervensi kombinasi massage tengkuk dan massage oksitosin sebagian besar ibu mengalami pengeluaran ASI < 6 jam setelah dilakukan massage yaitu sebanyak 18 orang $(75 \%)$ dan pada kelompok intervensi massage oksitosin sebanyak 13 orang $(54,2 \%)$.

Untuk mengetahui perbedaan waktu pengeluaran ASI pada masing-masing kelompok intervensi dapat dilihat pada tabel 04. Berdasarkan Tabel 04 menunjukkan bahwa kedua kelompok memiliki jumlah responden yang sama yaitu 24 orang. Kelompok intervensi kombinasi massage tengkuk dan massage oksitosin memiliki median 1,17 dan kelompok intervensi massage oksitosin 4,17. Begitupun dengan waktu pengeluaran ASI tercepat/minimum pada kelompok yang diberikan kombinasi massage tengkuk dan massage oksitosin yaitu 0,12 jam dan terlama/maksimum yaitu 26,55 jam. Sedangkan, kelompok massage oskitosin waktu pengeluaran ASI tercepat/ minimumnya yaitu 0,15 jam dan terlama/maksimum yaitu 34,25 jam. Nilai rerata dan simpangan baku pada kelompok intervensi kombinasi massage tengkuk dan massage oksitosin juga lebih kecil daripada kelompok intervensi massage oksitosin yaitu 3,35 jam dan 5,62 jam serta 6,87 jam dan 8,72 jam secara berturut-turut. Berdasarkan hasil uji statistik Mann Whitney dengan tingkat kepercayaan 95\% diperoleh nilai signifikan ( $\rho$-value) adalah 0,026 yang artinya $\mathrm{H}_{0}$ ditolak dan $\mathrm{Ha}$ diterima. Sehingga dapat disimpulan bahwa terdapat perbedaan waktu pengeluaran ASI antara responden yang diberikan intervensi kombinasi massage tengkuk dan massage oksitosin dan responden yang diberikan intervensi massage oksitosin. Perbedaan ini menunjukkan bahwa responden yang diberi intervensi kombinasi massage tengkuk dan massage oksitosin pengeluaran ASInya lebih cepat daripada responden yang diberikan intervensi massage oksitosin.

\section{PEMBAHASAN}

Hasil analisis univariat karakteristik responden menunjukkan bahwa karakteristik umur tertinggi yaitu rentang usia 20-35 tahun yakni $83,3 \%$ pada kelompok kombinasi massage tengkuk dan massage oksitosin dan $91,7 \%$ pada kelompok massage okitosin. Menurut peneliti rentang usia ini dapat mempengaruhi waktu pengeluaran ASI karena pada masa ini ibu telah matang dan siap secara jasmani dan sosial menghadapi kehamilan, persalinan, nifas, menyusui serta merawat bayinya.

Hal tersebut didukung oleh teori yang dikemukakan oleh Biancuzo bahwa ibu yang usianya kurang dari 35 tahun lebih banyak memproduksi ASI dibandingkan dengan ibu-ibu yang sangat muda $(<20$ tahun) yang produksi ASInya juga kurang banyak dilihat dari tingkat kematurannya (Biancuzzo, 2003). Hasil penelitian ini diperkuat oleh Suraatmaja yang menyatakan bahwa rentang usia 20-35 tahun lebih banyak memproduksi ASI dibandingkan ibu yang lebih tua. Penjelasan diatas memberikan gambaran bahwa ASI dipengaruhi oleh usia (Suraatmaja, 1997).

Karakteristik paritas tertinggi yaitu multipara yakni $75 \%$ pada kelompok kombinasi massage tengkuk dan massage oksitosin dan $79,2 \%$ pada kelompok massage oksitosin. Menurut peneliti, paritas dapat mempengaruhi waktu pengeluaran 
ASI karena pada ibu yang memiliki pengalaman persalinan dan menyusui sebelumnya akan lebih mudah untuk menyusui pada kelahiran berikutnya.

Hal tersebut didukung oleh Mardiyaningsih yang mengatakan bahwa pengalaman yang dimiliki ibu dalam menyusui dan merawat bayinya sebelumnya membuat ibu lebih yakin dapat berhasil dalam menyusui anaknya yang sekarang dan lebih memungkinkan pengeluaran ASI dapat lebih cepat dibandingkan primipara (Mardiyaningsih, 2010). Hasil penelitian ini juga sejalan dengan penelitian yang dilakukan oleh Madjid yang menunjukkan ibu-ibu yang baru pertama kali mempunyai anak (primipara) sering timbul masalah dalam menyusui, berbeda dengan ibu-ibu multipara yang sudah pernah menyusui sebelumnya. Sehingga diperoleh gambaran bahwa ASI dipengaruhi oleh paritas (Madjid, 2003).

Hasil analisis univariat menujukkan bahwa, responden yang waktu pengeluaran ASInya $<6$ jam setelah dilakukan massage pada kelompok kombinasi massage tengkuk dan massage oksitosin terbanyak $75 \%$ dibandingkan kelompok massage oksitosin hanya $54,2 \%$ dan penyebaran waktu pengeluaran ASInya yang merata pada waktu 6-24 jam dan > 24 jam. Hal ini menunjukkan bahwa pemberian intervensi kombinasi massage tengkuk dan massage oksitosin memberikan efek yang lebih maksimal dalam membantu pengeluaran ASI pada ibu postpartum.

Secara deskriptif, kombinasi massage tengkuk dan massage oksitosin dengan massage oksitosin memiliki perbedaan waktu pengeluaran ASI yang signifikan, dimana kelompok intervensi kombinasi massage tengkuk dan massage oksitosin memiliki 1 responden yang waktu pengeluaran ASInya dikelompok > 24 jam, sedangkan pada kelompok intervensi massage oksitosin terdapat 2 orang responden yang pengeluaran ASInya > 24 jam yaitu pada hari kedua dan ketiga, responden tersebut berada pada kelompok umur berisiko dan berada pada kelompok primipara. Meskipun demikian, secara deskriptif hasil penelitian ini menunjukkan bahwa kombinasi massage tengkuk dan massage oksitosin cenderung lebih efektif dalam mempercepat waktu pengeluaran ASI pada ibu yang berusia $<20$ tahun dan primipara.
Berdasarkan hasil analisis bivariat dalam penelitian ini, dapat dilihat bahwa rerata waktu pengeluaran ASI pada kelompok kombinasi massage tengkuk dan massage oksitosin yaitu 3,35 jam lebih cepat dengan pengeluaran ASI paling cepat adalah 0,12 jam dan paling lama adalah 26,55 jam, dibandingkan dengan kelompok massage oksitosin rerata waktu pengeluaran ASInya yaitu 6,87 jam dengan pengeluaran ASI paling cepat adalah 0,15 jam dan paling lama adalah 34,25 jam. Hal ini menunjukkan bahwa pemberian tindakan kombinasi massage tengkuk dan massage oksitosin pada ibu postpartum akan lebih efektif mempercepat waktu pengeluaran ASI dibandingkan dengan pemberian tindakan massage oksitosin.

Melalui kombinasi massage tengkuk dan massage oksitosin, yakni pada massage tengkuk, aksi pemijatan dari otot semispinalis yang menimbulkan kontraksi simultan dan letak punggung yang dekat dengan dada akan mempengaruhi hipofisis untuk memproduksi hormon oksitosin, prolaktin dan endorphin (Suharto, 2011). Kontraksi yang ditimbulkan merangsang keluarnya endorfin yang menenangkan sehingga mengurangi nyeri ibu menyusui dan membantu meredam stres emosional dengan demikian akan mempercepat suplai darah yang mengangkut oksitosin dan prolaktin yang diproduksi di hipofisis langsung dibawa ke adenohipofisis untuk masuk ke payudara ibu dan menyebabkan otot-otot disekitar alveoli berkontraksi untuk memproduksi ASI (Umar, 2014).

Dasar prinsip kerja massage tengkuk dan massage oksitosin adalah sama, yakni menurunkan faktor penghambat. Namun, proses awal pemijatan tengkuk pada otot semispinalis yang memperlancar aliran darah menuju hipofisis melalui arteri hipofisis inferior dan superior akan mengeluarkan hormon endorfin yang akan membuat ibu nyaman saat menyusui. Pada perasaan yang nyaman inilah proses pengeluaran prolaktin oleh hipofisis akan berlangsung (dibantu dengan hisapan bayi). Dengan kontraksi simultan yang dihasilkan oleh massage tengkuk maka sinyal dari hipofisis akan dengan lebih cepat diterima oleh hipotalamus untuk memproduksi hormon oksitosin (Sloane, 2003).

Massage oksitosin yang dilakukan juga bekerja dengan cara memberikan rasa nyaman pada ibu sehingga mengurangi 
inhibisi pengeluaran oksitosin, namun tidak menstimulasi secara langsung titik pengeluaran hormon utama yang mempengaruhi pengurangan inhibisi tersebut yaitu hormon endorfin. Massage oksitosin hanya membantu mempercepat kerja saraf parasimpatis untuk menyampaikan perintah ke otak bagian belakang agar mensekresikan hormon oksitosin. Sehingga pengeluaran air susu relatif lebih lambat jika dibandingkan dengan kombinasi massage tengkuk dan massage oksitosin yang langsung memberikan stimulus untuk pengeluaran hormon endorfin dan stimulus pengeluaran hormon oksitosin itu sendiri. Dapat disimpulkan bahwa intervensi kombinasi kedua massage ini yakni massage tengkuk dan massage oksitosin bekerja dua kali lebih cepat dibandingkan intervensi massage oksitosin saja untuk proses pengeluaran air susu.

Setelah dilakukan uji statistik Mann Whitney dengan tingkat kepercayaan 95\% diperoleh nilai $\rho$-value sebesar 0,026 atau $<0,05$, sehingga dapat diketahui bahwa terdapat perbedaan waktu pengeluaran ASI antara ibu yang diberikan kombinasi massage tengkuk dan massage oksitosin dan ibu yang diberikan massage oksitosin. Adapun hal ini disebabkan oleh faktor kenyamanan ibu, dimana ibu yang diberikan kombinasi massage tengkuk dan massage oksitosin mengatakan bahwa ibu merasa tubuhnya lebih rileks, rasa pegal dipunggung dan ketegangan leher dan tengkuk telah banyak berkurang setelah diberikan massage ini. Karena, pada waktu setelah persalinan, ibu berada dalam kondisi badan terlalu lelah, capek dan kurang istirahat, sehingga dapat mempengaruhi produksi dan pengeluaran ASInya. Pada saat seperti inilah peran massage tengkuk diperlukan untuk pengurangan ketidaknyamanan pada ibu menyusui dengan merangsang langsung pada sumber ketegangan, melalui proses ini akan membantu kelacaran pengeluaran ASI.

Hasil penilitian ini sejalan dengan teori yang dikemukakan dalam Umabarsari bahwa produksi ASI sangat dipengaruhi oleh faktor kejiwaan ibu, ibu yang merasa tertekan, sedih, kurang percaya diri, sakit, tidak nyaman dan berbagai bentuk ketegangan yang mempengaruhi emosionalnya akan menurunkan volume ASI bahkan tidak akan terjadi produksi ASI.
ASI dapat diproduksi degan baik jika ibu dalam keadaan tenang dan nyaman (Umbarsari, 2017). Umar menyebutkan bahwa untuk mengurangi nyeri ibu menyusui dan membantu meredam stres emosional dapat dilakukan dengan massage tengkuk. Massage tengkuk merangsang keluarnya endorfin yang menenangkan sehingga refleks oksitosin dan prolaktin menjadi lancar. Selain itu prosedur pemijatan tengkuk juga melibatkan suami sehingga akan meningkatkan jalinan kasih sayang anak, ibu dan ayah (Umar, 2014).

Sloane menyebutkan bahwa pemijatan tengkuk berperan dalam memperlancar pengeluaran ASI yang sedikit sehingga mampu mencukupi kebutuhan nutrisi bayi. Proses awal pemijatan pada otot semispinalis memperlancar aliran darah menuju hipofisis melalui arteri hipofisis inferior dan superior. Setelah rangsangan diterima, hipofisis akan mengeluarkan hormon endorfin yang akan membuat ibu nyaman saat menyusui. Pada perasaan yang nyaman inilah proses pengeluaran prolaktin oleh hipofisis akan berlangsung (dibantu dengan hisapan bayi) (Sloane, 2003).

Hasil penelitian ini juga didukung oleh penelitian Suryani yang dilakukan pada ibu postpartum hari pertama dan kedua diketahui bahwa berdasarkan hasil analisis data menggunakan uji-T sampel related didapatkan $t_{\text {hitung }}>t_{\text {Tabel }} \quad(11,500>2,045)$ dimana terdapat peningkatan volume produksi ASI pada ibu sebelum dan sesudah diberikan massase tengkuk dan massase otot pectoralis mayor, dengan demikian terdapat manfaat massase tengkuk dan massase otot pectoralis mayor terhadap pengeluaran ASI (Suryani, 2014).

Hasil penelitian ini juga diperkuat oleh penelitian Sebayang menunjukkan bahwa terdapat peningkatan volume produksi ASI pada ibu sebelum dan sesudah diberikan massase tengkuk dan massase otot payudara dengan kompres hangat. Pada penelitian tersebut menyatakan bahwa massage tengkuk memiliki pengaruh terhadap pengeluaran ASI, massage tengkuk tidak merangsang secara langsung reflex oksitosin atau let down reflex, namun massage tengkuk merangsang langsung pada sumber ketegangan dan stress (Sebayang, 2017).

Hasil penelitian yang dilakukan oleh Kause dkk menyebutkan bahwa rata-rata 
durasi pengeluaran kolostrum pada ibu postpartum normal adalah 13,6 jam sedangkan pada ibu dengan persalinan section caesarea adalah 22,6 jam (Kause, Trisetiyaningsih and Sukmawati, 2016).

Umbarsari dalam penelitiannya menyebutkan bahwa ada hubungan antara pijat oksitosin dan pengeluaran ASI pada ibu nifas, dimana ibu yang diberikan pijat oksitosin rerata waktu pengeluaran ASInya 5,15 jam lebih cepat dari rerata kelompok yang tidak diberikan pijat oksitosin 8,30 jam (Umbarsari, 2017).

Pada penelitian ini, keterbatasan yang dihadapi peneliti pada saat penelitian yaitu: Pada penelitian ini, peneliti menggunakan sampel paritas ibu postpartum secara keseluruhan. Dengan kriteria ini, peneliti memiliki kemudahan dalam pemenuhan sampel, karena tidak mengkhususkan pada satu jenis paritas saja. Namun, efektifitas kombinasi massage tengkuk dan massage oksitosin dan massage oksitosin tidak dapat diukur dengan maksimal karena pada ibu multipara dipengaruhi oleh faktor pengalaman menyusui sebelumnya sehingga banyak ibu multipara telah keluar ASInya sebelum dilakukan intervensi. Dukungan keluarga, kurangnya dukungan keluarga dalam pemberian ASI eksklusif sehingga keluarga merasa tidak perlu untuk diberikan massage yang membantu pengeluaran ASI kepada ibu. Waktu penelitian, akibat kesulitan dalam memenuhi kriteria sampel, peneliti membutuhkan waktu yang lebih lama untuk memenuhi jumlah sampel yang diinginkan.

\section{KESIMPULAN}

Berdasarkan hasil penelitian yang telah dilakukan, maka dapat ditarik adalah pemberian intervensi kombinasi massage tengkuk dan massage oksitosin pada ibu postpartum akan lebih efektif mempercepat waktu pengeluaran ASI dibandingkan dengan pemberian tindakan massage oksitosin. Berdasarkan uji Mann Whitney diperoleh nilai $\rho$-value 0,026 yang artinya ada perbedaan waktu pengeluaran ASI terhadap ibu yang diberikan kombinasi massage tengkuk dan massage oksitosin maupun massage oksitosin setelah 2 jam postpartum (kala IV persalinan).

\section{SARAN}

Saran penelitian meliputi Bidan Praktik Mandiri (BPM) Amanah diharapkan dapat memanfaatkan hasil penelitian ini sebagai sumber rujukan dalam memberikan pelayanan kesehatan khususnya melakukan sosialisasi serta menerapkan pemberian intervensi massage tengkuk dan massage oksitosin dalam memperlancar pengeluaran ASI ibu postpartum. Bagi institusi pendidikan diharapkan penelitian ini dapat ditindaklanjuti dalam bentuk pengabdian masyarakat agar dapat memberikan kontribusi kepada masyarakat. Bagi peneliti lain kiranya dapat melakukan penelitian dengan mengembangkan penelitian ini seperti lebih menspesifikkan karakteristik serta dapat menambahkan variabel lainnya seperti teknik massage tengkuk dan teknik massage oksitosin untuk mengukur volume pengeluaran atau produksi ASI.

\section{UCAPAN TERIMA KASIH}

Ucapan terima kasih sebesar-besarnya kepada pimpinan BPM Amanah Kota Palu yang memberikan kesempatan untuk menerima kami melakukan penelitian, dan berbagai pihak yang membantu terlaksananya penelitian ini.

\section{DAFTAR RUJUKAN}

Albertina, M. M. and S, R. (2015) 'Hubungan Pijat Oksitosin Dengan Kelancaran Produksi ASI Pada Ibu Postpartum Seksio Sesarea Hari Ke 2-3', Jurnal Husada Mahakam, 3(9), pp. 452-522.

Asih, Y. and Risneni (2016) Buku Ajar Asuhan Kebidanan Nifas Dan Menyusui, Dilengkapi dengan Evidance Based Practice dan Daftar Tilik Asuhan Nifas. Jakarta: TIM.

Badan Penelitian dan Pengembangan Departemen Kesehatan RI (2013) Riset Kesehatan Dasar: RISKESDAS 2013. Jakarta.

Badriah, D. L. (2014) Gizi Dalam Kesehatan Reproduksi. Bandung: Refika Aditama.

Biancuzzo, M. (2003) Breastfeeding the Newborn: Clinical Strategies For Nurses. St. Louis: Mosby Company.

Dinas Kesehatan Kota Palu (2016) Profil Kesehatan Kota Palu Tahun 2016. Kota Palu.

Dinas Kesehatan Provinsi Sulawesi Tengah (2016) Profil Kesehatan Sulawesi Tengah Tahun 2016. Kota Palu.

Endah, S. N. and Masdinarsah, I. (2011) 'Pengaruh Pijat Oksitosin Terhadap Pengeluaran Kolostrum pada lbu 
Post Partum di Ruang Kebidanan Rumah Sakit Muhammadiyah Bandung Tahun 2011', Jurnal Kesehatan Kartika, 1(12), pp. 1-9.

Kause, M. N., Trisetiyaningsih, Y. and Sukmawati, A. S. (2016) 'Onset Pengeluaran Kolostrum Persalinan Normal Lebih Cepat Daripada Persalinan Sectio Caesarea', Media IImu Kesehatan, 5(3), pp. 193-199.

Lemeslow, S. et al. (1997) Besar Sampel dalam Penelitian Kesehatan. Yogyakarta: Gadjah Mada University Press.

Lestari, W., Sari, D. F. and Muthia, G. (2013) 'Hubungan Inisiasi Menyusu Dini (IMD) dengan Waktu Keluarnya ASI pada lbu Post Partum di Puskesmas Lubuk Buaya Padang', E-Journal STIKES Mercubaktijaya, pp. 1-9.

Madjid (2003) Perilaku Pemberian ASI pada Masyarakat di Daerah Cirebon, Cianjur, Kediri dan Blitar. Universitas Airlangga.

Mardiyaningsih, E. (2010) Efektifitas Kombinasi Teknik Marmet dan Pijat Oksitosin Terhadap Produksi ASI Ibu Post Seksio Sesarea di Rumah Sakit Wilayah Jawa Tengah. Universitas Indonesia.

Noer, R. N., Muis, S. F. and Aruben, R. (2011) 'Praktik Inisiasi Menyusus Dini dan Pemberian ASI Eksklusif Studi Kualitati Pada Dua Puskesmas, Kota Semarang', $M$ Med Indonesia, 45(03), pp. 144-150.

Rini, S. and Kumala, D. F. (2016) Panduan Asuhan Nifas dan Evidence Based Practice. Yogyakarta: Deepublish.

Sebayang, W. (2017) 'Manfaat Massase Tengkuk dan Kompres Hangat Payudara Terhadap Pengeluaran Kolostrum ASI pada Ibu Postpartum di Klinik Pratama Rosni Alizar Medan Tahun 2017', Jurnal IImiah Kebidanan Imelda, 3(2), pp. 267270.

Sloane, E. (2003) Anatomi dan Fisiologi Untuk Pemula. Jakarta: EGC.

Suharto (2011) Mc Kenzie Pada Nyeri
Tengkuk. Available at: http://www.artikel.indonesianrehabeq uipment.com.

Suraatmaja (1997) Seri Gizi Klinik ASI Petunjuk untuk Tenaga Kesehatan. Jakarta: Penerbit Buku Kedokteran.

Suryani, I. (2014) 'Manfaat Massase Tengkuk dan Massase Otot Pectoralis Mayor Terhadap Pengeluaran ASI pada Ibu Postpartum Hari Ke 1 dan Hari Ke 2', Jurnal Akademi Kebidanan Graha Mandiri, pp. 41-45.

Syandi, I. N. (2017) 'Efektivitas Metode Reserve Pressure Softening Terhadap Enggorgement Pada Ibu Post Partum Di Rsud Prof. Dr. Margono Soekardjo Purwokerto', Jurnal Fakultas IImu Kesehatan UMP, pp. 13-41.

Tadesse, T., Mesfin, F. and Chane, T. (2016) 'Prevalence and Associated Factors of Nonexclusive Breastfeeding of Infants During the First Six Monhts in Rural Area of Sorro District, Southern Ethiopia: A Cross-sectional Study', International Breastfeeding Journal, 11(25), pp. 18. doi: 10.1186/s13006-016-0085-6.

Ulfah, R. R. M. (2013) Efektivitas Pemberian Teknik Marmet Terhadap Pengeluaran Asi Pada Ibu Menyusui 0-6 Bulan Di Wilayah Kerja Puskesmas Arjasa Kabupaten Jember. Universitas Jember.

Umar, N. (2014) Multitasking Breastfeeding Mama. Jakarta: Pustaka Bunda.

Umbarsari, D. (2017) 'Efektifitas Pijat Oksitosin Terhadap Pengeluaran ASI Di RSIA Annisa', Jurnal IImu Kesehatan, 1(1), pp. 11-17.

Wiji, R. N. (2013) ASI dan Panduan Ibu Menyusui. Yogyakarta: Nuha Medika.

World Health Organization (2016) World Health Statistik 2016: Monitoring Health for SDGs, Sustaniable Development Goals. France: WHO Press.

Zerlina, L. (2014) Tanya Jawab Seputar Ibu Hamil. Klaten: Galmas Publisher. 
Tabel 01

Distribusi Responden Berdasarkan Umur dan Paritas pada Kelompok Kombinasi Massage Tengkuk dan Massage Oksitosin di Bidan Praktik Mandiri (BPM) Amanah Tahun 2018.

\begin{tabular}{cccc}
\hline \multirow{2}{*}{ Karakteristik } & \multicolumn{2}{c}{$\begin{array}{c}\text { Kombinasi Massage Tengkuk } \\
\text { dan Massage Oksitosin }\end{array}$} \\
\cline { 3 - 4 } & & $\mathbf{f ( 2 4 )}$ & $\%$ \\
\hline \multirow{3}{*}{ Umur } & <20 Tahun & 4 & 16,7 \\
& 20-35 Tahun & 20 & 83,3 \\
\multirow{2}{*}{ Paritas } & $>35$ Tahun & - & - \\
\hline & Primipara & 6 & 25 \\
& Multipara & 18 & 75 \\
\hline
\end{tabular}

Tabel 02

Distribusi Responden Berdasarkan Umur dan Paritas pada Kelompok Massage Oksitosin di Bidan Praktik Mandiri (BPM) Amanah Tahun 2018.

\begin{tabular}{cccc}
\hline \multirow{2}{*}{ Karakteristik } & \multicolumn{2}{c}{ Massage Oksitosin } \\
\cline { 3 - 4 } & & $\mathbf{f ( 2 4 )}$ & $\mathbf{\%}$ \\
\hline \multirow{2}{*}{ Umur } & $<20$ Tahun & 2 & 8,3 \\
& 20-35 Tahun & 22 & 91,7 \\
\multirow{2}{*}{ Paritas } & $>35$ Tahun & - & - \\
& Primipara & 5 & 20,8 \\
& Multipara & 19 & 79,2 \\
\hline
\end{tabular}

Tabel 03

Distribusi Waktu Pengeluaran ASI pada Kelompok Kombinasi Massage Tengkuk dan Massage Oksitosin dengan Kelompok Massage Oksitosin di Bidan Praktik Mandiri (BPM) Amanah Tahun 2018.

\begin{tabular}{ccccc}
\hline \multirow{2}{*}{$\begin{array}{c}\text { Waktu } \\
\text { Pengeluaran ASI }\end{array}$} & $\begin{array}{c}\text { Kombinasi Massage } \\
\text { Tengkuk dan Massage } \\
\text { Oksitosin }\end{array}$ & $\begin{array}{c}\text { Kelompok Massage } \\
\text { Oksitosin }\end{array}$ \\
\cline { 2 - 6 } & $\mathbf{f}$ & $\%$ & f & $\%$ \\
\hline <6 Jam & 18 & 75 & 13 & 54,2 \\
6-24 Jam & 5 & 20,8 & 9 & 37,5 \\
>24 Jam & 1 & 4,2 & 2 & 8,3 \\
\hline Total & 24 & 100 & 24 & 100 \\
\hline
\end{tabular}

Tabel 04.

Uji Perbedaan Waktu Pengeluaran ASI pada Kelompok Kombinasi Massage Tengkuk dan Massage Oksitosin dengan Kelompok Massage Oksitosin di Bidan Praktik Mandiri (BPM) Amanah Tahun 2018.

\begin{tabular}{ccccc}
\hline Kelompok & N & $\begin{array}{c}\text { Median } \\
\text { (Minimum- } \\
\text { Maksimum) }\end{array}$ & Rerata \pm s.b & o-value \\
\hline $\begin{array}{c}\text { Kelompok Kombinasi } \\
\text { Massage Tengkuk dan } \\
\text { Massage Oksitosin }\end{array}$ & 24 & $\begin{array}{c}1,17 \\
(0,12-26,55)\end{array}$ & $3,35 \pm 5,62$ & \\
\hline $\begin{array}{c}\text { Kelompok Massage } \\
\text { Oksitosin }\end{array}$ & 24 & $\begin{array}{c}4,17 \\
(0,15-34,25)\end{array}$ & 6,026 \\
& & & & \\
\hline
\end{tabular}

